\title{
Optimized monitoring sites for detection of biodiversity trends in China
}

\author{
Haigen $\mathrm{Xu}^{1} \cdot{\mathrm{Mingchang} \mathrm{Cao}^{1} \cdot \mathrm{Yi} \mathrm{Wu}}^{2} \cdot \mathrm{Lei} \mathrm{Cai}^{3} \cdot$ \\ Yun $\mathrm{Cao}^{1} \cdot$ Hui Ding ${ }^{1} \cdot$ Peng Cui ${ }^{1} \cdot \mathrm{Jun} \mathrm{Wu}^{1}$. \\ Zhi Wang ${ }^{1} \cdot$ Zhifang Le $^{1} \cdot$ Xiaoqiang $\mathrm{Lu}^{1} \cdot \mathrm{Li} \mathrm{Liu}^{1} \cdot$ \\ Jiaqi $\mathbf{L i}^{1}$
}

Received: 2 December 2016/Revised: 18 March 2017/ Accepted: 30 March 2017/

Published online: 10 April 2017

(C) The Author(s) 2017. This article is an open access publication

\begin{abstract}
Properly designed monitoring networks can generate data to understand status and trends of biodiversity, and to assess progress towards conservation targets. However, biodiversity monitoring is often affected by poor sampling design. We proposed an approach to choosing optimized monitoring sites among large areas. Based on comprehensive distribution data of 34,284 vertebrates and vascular plants from 2376 counties in China, we selected 564 optimized monitoring sites (counties) through complementarity analysis and pre-existing knowledge of nature reserves. The optimized monitoring sites are complementary to each other and reasonably distributed, to ensure that maximum species are covered while the total number of sites and monitoring costs are minimized. Incongruence of optimized monitoring sites among different taxa indicates that taxa with different ecological features should be selected for large-scale monitoring programmes. The results of this study have been applied in the design and operation of China Biodiversity Observation Network.
\end{abstract}

Keywords Complementarity analysis · Endemism · Sampling design · Threatened species · Vascular plants $\cdot$ Vertebrates $\cdot$ Biodiversity observation network · Essential biodiversity variables

Communicated by Dirk Sven Schmeller.

Electronic supplementary material The online version of this article (doi:10.1007/s10531-017-1339-3) contains supplementary material, which is available to authorized users.

Haigen $\mathrm{Xu}$

xhg@nies.org

1 Nanjing Institute of Environmental Sciences, Ministry of Environmental Protection, 8 Jiangwangmiao St., PO Box 4202, Nanjing 210042, China

2 College of Forest Resources and Environment, Nanjing Forestry University, Nanjing 210037, China

3 Department of Natural Ecology Conservation, Ministry of Environmental Protection, Beijing 100035, China 


\section{Introduction}

Biodiversity has continued to decline over the past four decades (Butchart et al. 2010; Tittensor et al. 2014). Parties to the Convention on Biological Diversity (CBD) has adopted the Strategic Plan for Biodiversity 2011-2020 and set the Aichi Targets to 'take effective and urgent action to halt the loss of biodiversity' (CBD 2010). Biodiversity monitoring is useful for identifying species in decline or at risk of extinction (Gerber et al. 1999; Shea and Mangel 2001), determining sustainable levels of utilization (Hauser et al. 2006), and assessing the effectiveness of conservation measures (Campbell et al. 2002). Biodiversity monitoring can provide timely and accurate data for regional or national management needs and policy making (Green et al. 2005; Haughland et al. 2010; Honrado et al. 2016). Lack of monitoring data can reduce the capacity for informed decision-making and timely reporting on progress towards conservation targets (DeWan and Zipkin 2010). It is crucial to detect and understand spatial-temporal biodiversity changes through monitoring for better allocation of conservation efforts and assessment of the progress towards relevant strategies and targets (Pereira and Cooper 2006; Pereira et al. 2013).

The design of a monitoring network requires cost-efficient allocation of monitoring sites across space (Amorim et al. 2014; Vicente et al. 2016), to ensure that monitoring sites are distributed in the most informative areas and the total number of sites are minimized (Amorim et al. 2014; Carvalho et al. 2016; Honrado et al. 2016). In design of monitoring networks, researchers usually divide the target region into grids and select grids through relevant sampling strategies. For instance, the breeding bird survey (BBS) in the UK adopted approximately 3000 1-km grids that were chosen through stratified random sampling (Harris et al. 2016), and biodiversity monitoring in Switzerland (BDM) implemented systematic sampling to monitor its biodiversity (BDM Coordination Office 2014). Nevertheless, sampling methods for species-level monitoring network, such as sampling strategies, estimate of effective sample size, standardized field protocols, statistical models to interpret monitoring data are still inadequate due to large number of species involved and the high cost of traditional survey methods (Noon et al. 2012). Monitoring for conservation is challenging as accurate estimation of species abundance or occurrence may be hampered by large geographic areas or inaccurate detection of species (Yoccoz et al. 2001; MacKenzie 2006; Pereira et al. 2013). Current biodiversity monitoring programmes often suffer insufficient taxonomic and spatial coverage. The priority task is to significantly expand the coverage of biological taxa, habitats and geographical regions, which will in turn require the design of sampling regimes that are properly selected across space and taxa (Balmford et al. 2003). Complementarity analysis is commonly used for systematic conservation planning (Reyers et al. 2000; Faith et al. 2003; Williams et al. 2006). Through complementarity analysis, minimal areas can be selected to protect maximal biodiversity (species, habitats or ecosystems) (Cabeza and Moilanen 2001). We explored for the first time the utility of complementarity analysis for the selection of monitoring sites.

China is one of the 'megadiversity' countries in the world (Liu et al. 2003; Brooks et al. 2006). However, it is facing huge pressures from the largest population and economic growth (Liu and Diamond 2005), which poses threats to biodiversity. Currently, China has set up a series of nationwide monitoring network for ecosystems, such as China ecosystem research network (CERN) and China forest ecological research network (CFERN) (Xu et al. 2012). Although the preliminary framework for ecosystem-level monitoring has been basically established, species-level monitoring in China remains rare and faces various 
challenges, such as poor sampling design and low spatial and species coverage (Xu et al. 2012).

Here, we present an approach to designing monitoring networks for vertebrates and vascular plants in terrestrial and inland water ecosystems across China. The overall objective of the proposed monitoring networks is to detect changes in species composition, distribution and population dynamics, assess major threats to target species and evaluate the efficiency of conservation policy. It contains two steps: (i) selection of monitoring sites; and (ii) implementation of monitoring activities in selected monitoring sites, that are establishment of plots and line and/or point transects, training of human resources, and standardization of field protocols and quality control. In this study, we identified optimized monitoring sites based on a comprehensive database of 34,284 vertebrates and vascular plants from 2376 counties across China through complementarity analysis and heuristic knowledge of nature reserves. The major criterion in the selection of monitoring sites is to ensure the coverage of maximum species and minimization of network size (number of sites). We considered all species, threatened species and species endemic to China of mammals, birds, amphibians, reptiles, inland water fishes and vascular plants.

\section{Methods}

\section{Data}

We used a database of the geographical distribution for 561 mammal species, 1347 bird species, 387 reptile species, 359 amphibian species, 1111 inland water fish species, and 30519 vascular plant species from 2376 counties (their mean size: $3908.7 \mathrm{~km}^{2}$; standard deviation: $9287.6 \mathrm{~km}^{2}$ ) across China (Xu et al. 2013, 2015, 2016). As far as we know, it is the most comprehensive database ever developed in the country. Marine species, cultivated or bred species, and alien species were eliminated from this study. We adopted 'county' as the basic sampling unit in this study (the sampling population across China is 2376 counties) (Xu et al. 2015, 2016). The richness data were collected from (i) species distribution information from over 1000 monographs and representative papers on fauna and flora across China; (ii) record information of specimens in herbaria of the Chinese Academy of Sciences and relevant universities; and (iii) field surveys in different regions (Xu et al. 2013, 2015, 2016). We considered respectively all species, threatened species and species endemic to China. According to the IUCN Red List Categories and Criteria (Version 3.1), threatened species are those species that are critically endangered, endangered, or vulnerable.

Main threats to biodiversity in China include fragmentation and loss of habitats, overexploitation of natural resources, pollution, invasion of alien species and climate change (Ministry of Environmental Protection of China 2014). We selected population density, GDP density and road density to represent major threats to biodiversity. Data on population density and GDP density of counties were obtained from provincial statistical bureaus, and data on road density were obtained from Ministry of Transport of China (http://www.moc.gov.cn/). Data on above three major threats were recorded in 2010.

Data on the locality, area, conservation targets and year of establishment of nature reserves were obtained from the statistics of the Ministry of Environmental Protection of China (http://www.mep.gov.cn). The zoning map of phytogeographic regions and zoogeographical regions were respectively from the study of Wu et al. (2011) and Zhang 
(2011). The map of watersheds in China was from the website of National Administration of Surveying, Mapping and Geoinformation with a scale of 1:4,000,000 (http://www.sbsm. gov.cn/article/zxbs/dtfw/).

\section{Essential sites for monitoring}

Essential sites were selected before complementarity analysis. To identify essential sites for monitoring, we selected nature reserves that harbor representative regional biodiversity and the capacity to monitor biodiversity as essential nature reserves. The essential nature reserves were assessed in terms of their conservation targets, regional distribution and monitoring capability. Criteria to select essential nature reserves include: (i) embracing major national nature reserves; (ii) focusing on the conservation targets of nature reserves and maintaining regional balance; and (iii) including existing important monitoring sites among CERN and CFERN. We considered counties in which essential nature reserves are distributed as essential sites for monitoring. When an essential nature reserve is distributed across several counties, the county with the highest richness was selected as essential sites for monitoring and noted as priority county. We then calculated the complementarity score between the priority county and other counties holding the nature reserve (see details in next paragraph). If the complementarity score of a county with the priority county was larger than 0.8 , this county was also selected as an essential site.

\section{Complementarity analysis}

Optimized monitoring sites (counties) were selected by complementarity analysis under scenarios of different distances between counties and species coverage. According to the study of Colwell and Coddington (1994), the complementarity score $\left(C_{j k}\right)$ between county $j$ and county $k$ was defined as follows:

$$
C_{j k}=1-V_{j k} / S_{j k}
$$

where $S_{j k}=S_{j}+S_{k}-V_{j k} ; \mathrm{S}_{j}$ is the number of species in county $j ; S_{k}$ is the number of species in county $k$; $V_{j k}$ is the number of common species both in county $j$ and county $k$. The resulting $C_{j k}$ ranges between 0 and 1 .

Based on the study of $\mathrm{Xu}$ (2013), the algorithm of complementarity analysis was as follows:

(i) Set goals for the design of monitoring network: covering maximal number of species within minimal sampling sites and embracing all nationally protected species;

(ii) Select essential sites for monitoring;

(iii) Select other sites:

(a) Set species coverage $90 \%$ of species of a taxon;

(b) Set a distance of $50 \mathrm{~km}$ between counties (calculated as the distance between centroids of counties);

(c) For each county belonging to U, which is the set of all counties excluding essential sites, calculate the complementarity score between the county and essential sites for nationally protected species; select the county with the highest complementarity score and a distance between the county and essential sites larger than $50 \mathrm{~km}$ (Ties for complementarity score were 
broken by selecting the county with the highest species richness) and include this county in the list of essential sites, until the selected counties cover all nationally protected species of the taxon;

(d) For all species of the taxon, repeat the process in (c), until the selected counties cover no less than $90 \%$ of species of the taxon.

(e) Enlarge the distance to $100,150,200,250$ and $300 \mathrm{~km}$, progressively, repeat the processes in (c) and (d), to select the counties meeting condition (a);

(f) Repeat process from (a) to (e), to select counties with a species coverage of 95,98 or $100 \%$ under different distances.

The algorithm first selected essential sites, then selected other sites based on species coverage targets and control distances between counties. There were four species coverage targets: 90, 95, 98 and $100 \%$. If all essential sites meet a given species coverage target, the process is ended. Otherwise, all species found in essential sites were excluded from further consideration, the algorithm searched for other sites (counties) with the greatest number of species that were not already selected (Dobson et al. 1997) and included this selected site (county) in the list of essential sites. This process continues until a given species coverage target is met. Monitoring sites should be apart from each other as much as possible to ensure independence and avoid spatial autocorrelation between sites (Carvalho et al. 2016). Six distance intervals $(50,100,150,200,250$ and $300 \mathrm{~km})$ were examined. The distance between selected sites must always be larger than relevant distance value. The algorithm was run respectively for all species, threatened species and endemic species of all six taxa (Reyers et al. 2000).

Kendall's rank partial correlations were used to analyze the relations between species richness and the number of monitoring sites in a zoning system and remove the effects of area on the number of monitoring sites (Xu et al. 2008). Species richness, the number of monitoring sites plus one, and area of regions were $\log _{10}$ transformed before analysis. SPSS version 16.0 was used for partial correlation analysis and the Software packages R, version 2.15 (R Development Core Team 2012) was used for complementarity analysis.

\section{Results}

\section{Essential monitoring sites}

In terms of conservation targets, regional distribution and monitoring capacity of nature reserves, 196 essential nature reserves were selected, which were mostly national nature reserves. Accordingly, 36 essential monitoring sites for mammals, 52 for birds, 21 for reptiles, 24 for amphibians, 40 for inland water fishes and 84 for plants were selected (Fig. S1).

\section{Optimized monitoring sites}

Goals for the design of monitoring networks were determined based on the results of complementarity analysis under scenarios of different distances and species coverage (Fig. 1; Tables S1-S6). Meanwhile, costs (number of sites) were taken into account. The number of sites increased rapidly with an increase in coverage of species for plants and fishes. Therefore, we selected a threshold of species coverage of $90 \%$ for plants and fishes 

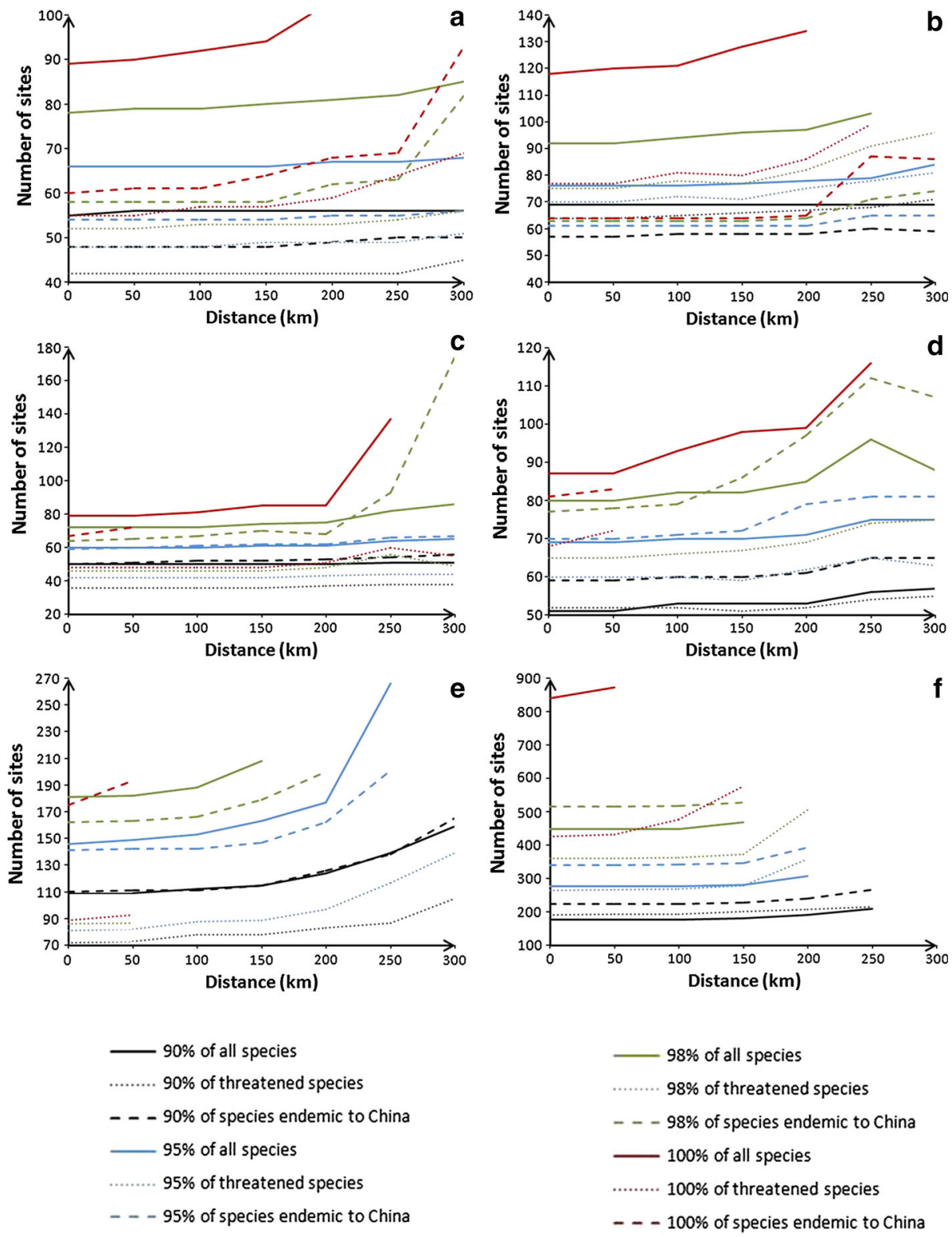

Fig. 1 Number of monitoring sites for vertebrates and vascular plants calculated by complementarity analysis under different distance and species coverage scenarios. Lines where the number of monitoring sites does not exist mean that there is no solution under the distance and species coverage. Monitoring sites should be apart from each other as much as possible to ensure independence and avoid spatial autocorrelation between sites. The distance between selected sites must always be larger than relevant distance value. a Mammals, $\mathbf{b}$ birds, $\mathbf{c}$ reptiles, $\mathbf{d}$ amphibians, $\mathbf{e}$ inland water fishes, $\mathbf{f}$ vascular plants

(Tables S5, S6). The number of sites for mammals, birds, reptiles and amphibians increased relatively slow compared with that for plants and fishes. Accordingly, we selected the highest species coverage (100\%) for mammals, birds, reptiles and amphibians 
(Tables S1-S4). We set distance thresholds of $50 \mathrm{~km}$ for plants and $100 \mathrm{~km}$ for most vertebrates, according to changes in the number of sites for all species, threatened species and endemic species. Therefore, the goals for the design of monitoring networks were set as follows: (i) Covering 100\% of species of mammals, birds, reptiles and amphibians and $90 \%$ of species of inland water fishes and vascular plants; (ii) keeping $100 \mathrm{~km}$ apart between any two sites for vertebrates and $50 \mathrm{~km}$ apart for vascular plants.

We obtained monitoring sites for all species, threatened species and endemic species of the six taxa based on the above-mentioned goals (Figs. S2-S7). The monitoring sites for all species, threatened species and endemic species of a taxon were merged into optimized monitoring sites (Fig. 2; Table 1). The overlaps between the optimized monitoring sites of any two taxa range between 8.7 and $20.1 \%$ (Table 2). There were more monitoring sites in southern China than in northern China, and more sites in eastern China than in western China (Fig. 2). The total number of optimized monitoring sites for six taxa is 564
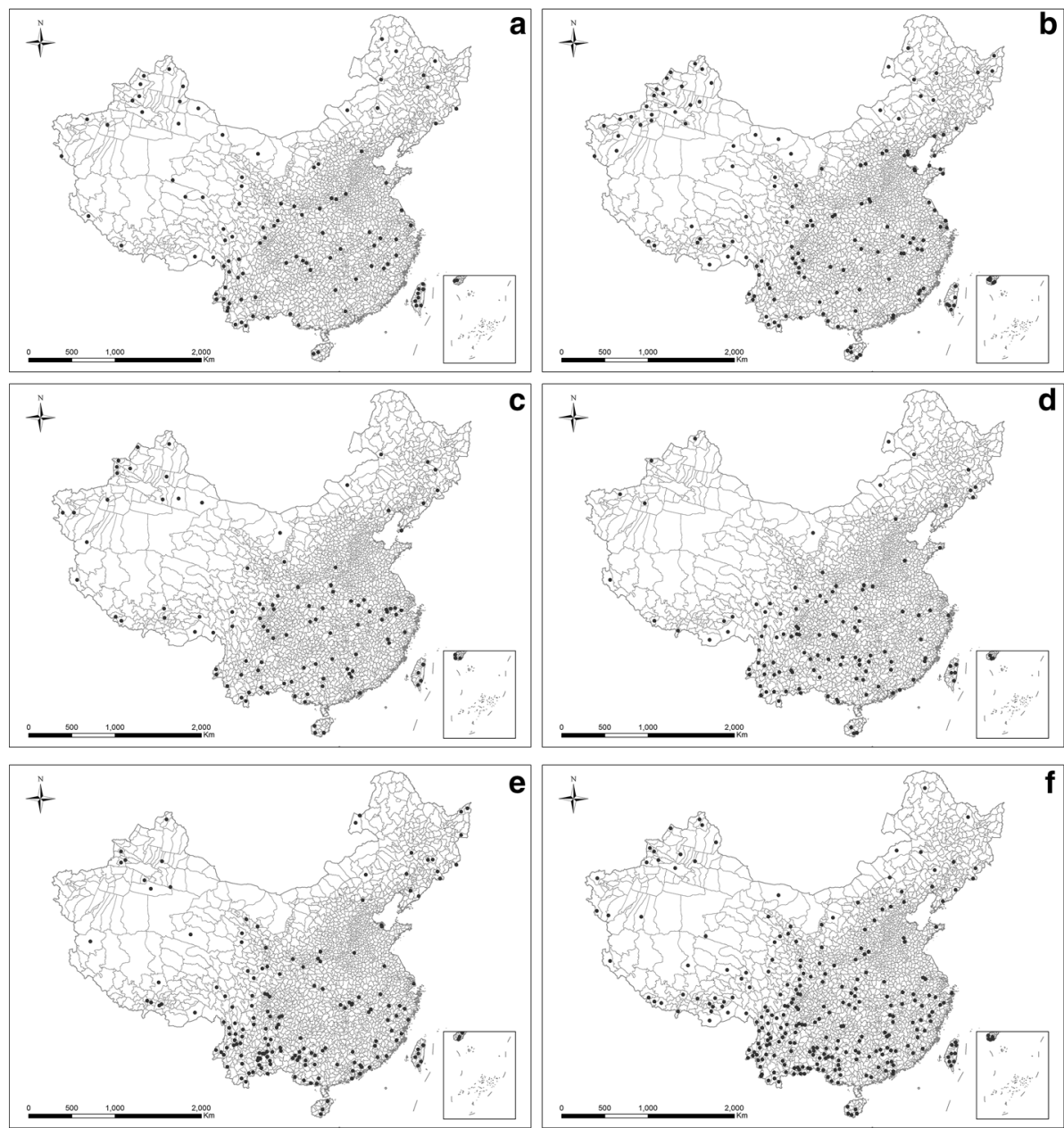

Fig. 2 Optimized monitoring sites for vertebrates and vascular plants in China. a mammals, b birds, c reptiles, $\mathbf{d}$ amphibians, $\mathbf{e}$ inland water fishes, $\mathbf{f}$ vascular plants 
Table 1 Number of optimized monitoring sites for vertebrates and vascular plants in China

\begin{tabular}{ll}
\hline Taxa & Number of optimized monitoring sites \\
\hline Mammals & 107 \\
Birds & 148 \\
Reptiles & 104 \\
Amphibians & 116 \\
Inland water fishes & 171 \\
Vascular plants & 264 \\
The union of the optimized monitoring sites for six taxa & 564 \\
\hline
\end{tabular}

Table 2 Overlaps between optimized monitoring sites for different taxa

\begin{tabular}{llllll}
\hline Taxa & Mammals & Birds & Reptiles & Amphibians & Fishes \\
\hline Birds & 15.9 & & & & \\
Reptiles & 14.7 & 14.5 & & \\
Amphibians & 12.6 & 13.8 & 18.9 & 10.0 & 15.7 \\
Fishes & 10.3 & 12.3 & 8.7 & 15.9 & 16.5 \\
Vascular plants & 20.1 & 16.7 & & & \\
\hline
\end{tabular}

Overlap (\%) is defined as $a \times 100 \% / b$, where $a$ is the number of common sites between the optimized monitoring sites of two taxa, and $b$ is the number of total sites of the optimized monitoring sites of two taxa

(Table 1), owning to overlaps between some monitoring sites for different taxa. The optimized monitoring sites represent a set of counties that complement each other in terms of species composition with minimized sampling size and monitoring costs. It indicates the different role of the optimized monitoring sites where monitoring should be carried out for only one taxon in most sites while several or all of six taxa in other sites.

\section{Discussion}

This study demonstrated an approach to allocating minimum monitoring sites to the most informative areas. We showed spatial data of species richness, endemism and threat can be combined with pre-existing knowledge of nature reserves in order to optimize monitoring networks across large areas. In this study, the number of monitoring sites increased with the increase in species coverage (Tables S1-S6). For instance, the number of monitoring sites for all vascular plants increased from 177 to 871 , when the species coverage changed from 90 to $100 \%$, under the circumstance of keeping over $50 \mathrm{~km}$ apart between any two sites (Table S6). It indicates that more monitoring sites should be included to cover more species. Meanwhile, distance has effects on the selection of monitoring sites. The number of monitoring sites for all vascular plants changed from 177 to 210 when the distance increased from 0 to $250 \mathrm{~km}$ under $90 \%$ species coverage (Table S6). Based on the adopted algorithm, we begin with the county that has the highest complementarity score and 
sequentially include counties that add the most unrepresented species (Reyers et al. 2000). When distance is increased, more counties should be selected among counties with lower species richness in order to meet species coverage target.

Monitoring sites for vascular plants were mainly distributed along large mountains, monitoring sites for reptiles, amphibians and fishes were distributed along the Qinling Mountains and Huaihe River and further south, and monitoring sites for mammals and birds were distributed evenly throughout China (Fig. 2). There are very few monitoring sites in the middle of Kunlun Mountains and Hoh Xil Mountains of Qinghai-Tibet Plateau where few species are distributed owning to extreme cold and arid conditions (Xu et al. 2008). Overlaps between optimized monitoring sites for different taxa were low (less than $21 \%$ ) (Table 2). It indicates that optimized monitoring sites among different taxa are not congruent. Our findings confirmed the conclusion of low congruence among biodiversity hotspots of different taxa (Orme et al. 2005). The results suggest that we should consider taxa with different ecological requirements in large-scale monitoring schemes.

We tested the correlations between the number of monitoring sites and species richness in different zoogeographical regions (Zhang 2011), phytogeographic regions (Wu et al. 2011) and watersheds (Figs. S8-S10). The correlations were positive and mostly significant for different taxa and zoning systems (Table 3). It indicates the high representativeness of optimized monitoring sites for regional ecological features. The insignificant correlation between the number of bird monitoring sites and bird species richness in zoogeographical regions (Table 3) might result from the special bird fauna in Xinjiang. As this region is located in the Central Asian flyway, most of its bird species are Central Asian and Northern species and thus different from species from other regions. Although bird species richness in the Mongolia-Xinjiang region was the second lowest, it covered the maximum number of bird monitoring sites among seven zoogeographical regions (Fig. S8).

Currently, China has experienced a very rapid growth in population and economy. However, its rich biodiversity are suffering the threats from the very strong and fast changes in terms of economy, land use, pollution, fragmenting infrastructure etc. To effectively capture the status and trends of biodiversity, human impact on biodiversity should be incorporated into the design of biodiversity monitoring network. Here, we used the data on population density, GDP density and road density to represent major threats to biodiversity, and verified the rationality of the designed monitoring network. Each indicator was normalized separately to the range of 0-100 using the minimum-maximum normalization method (Yang et al. 2016), with 100 the largest and 0 the smallest. The

Table 3 Correlations (Kendall's rank) between the number of optimized monitoring sites and species richness in different zoning systems, with the effects of area removed

\begin{tabular}{|c|c|c|c|c|c|c|}
\hline Zoning systems & Mammals & Birds & Reptiles & Amphibians & Fishes & $\begin{array}{l}\text { Vascular } \\
\text { plants }\end{array}$ \\
\hline $\begin{array}{l}\text { Zoogeographical regions } \\
\quad(\mathrm{n}=7)\end{array}$ & $0.85^{*}$ & 0.78 & $0.87^{*}$ & $0.95^{* *}$ & & \\
\hline $\begin{array}{l}\text { Phytogeographic regions } \\
\quad(\mathrm{n}=7)\end{array}$ & & & & & & $0.97 * *$ \\
\hline Watersheds $(\mathrm{n}=12)$ & & & & & $0.87 * * *$ & \\
\hline
\end{tabular}

The number of optimized monitoring sites +1 , species richness, and area of regions are $\log _{10}$ transformed before analysis. * $\mathrm{p}<0.05 ; * * \mathrm{p}<0.01$; *** $\mathrm{p}<0.001$ 
average value of the three normalized indicators was expressed as the value of Threat Index (TI) for each county. The mean TI was 6.56 for 2376 counties across the whole country. The mean TI for 564 proposed monitoring sites in this study was 4.64, which was obviously larger than that (3.81) of 246 counties where 196 essential nature reserves were distributed. Among the 564 proposed monitoring sites, 98 monitoring sites' TI exceeded the average national level of 6.56, and 230 monitoring sites' TI exceeded 3.81 in the essential nature reserves (Fig. S11). Moreover, the mean values of population density, GDP density and road density for 2376 counties were 440.43 people $/ \mathrm{km}^{2}, 1788.64$ ten thousand yuan $/ \mathrm{km}^{2}$, and $278.70 \mathrm{~m} / \mathrm{km}^{2}$, respectively. 75, 62, and 107 monitoring sites showed a higher level than mean values for 2376 counties respectively in terms of population density, GDP density and road density. Population density, GDP density or road density in half of the monitoring sites exceeded 114.57 people $/ \mathrm{km}^{2}, 158.93$ ten thousand yuan $/ \mathrm{km}^{2}$, and $173.61 \mathrm{~m} / \mathrm{km}^{2}$, respectively. Therefore, we consider that the gradient of stressors has been relatively well addressed within the proposed monitoring network.

The presented sampling framework aims to detect biodiversity status and trends in different habitat types across large-scale areas. It can be used as a reference for the design and operationalization of practical biodiversity monitoring schemes. Theoretically, all mammal, bird, reptile and amphibian species and $90 \%$ of inland water fish and vascular plant species can be covered by optimized monitoring sites. However, species coverage is reduced in practice because of low detection probabilities (Kéry and Schmid 2004), and limited budget and human resources. Therefore, the number of actual monitoring sites may exceed 564 to address the impacts of low detection probabilities and other management issues. However, the optimized monitoring sites can be used as a starting point to design and fine tune practical monitoring schemes.

The Group on Earth Observations Biodiversity Observation Network (GEO BON) has developed the concept of Essential Biodiversity Variables (EBVs) (Pereira et al. 2013). The aim of the EBVs is to identify a minimum set of variables that can be used to inform scientists, managers and the public on biodiversity trends (Pereira et al. 2013; Proença et al. 2016). GEO BON aggregated candidate variables into six classes: "genetic composition," "species populations," "species traits," "community composition," "ecosystem structure," and "ecosystem function" (Pereira et al. 2013). EBVs allow for the averaging of trends of multiple species across multiple locations, and their measurement captures ongoing changes in the status of biodiversity (Pereira et al. 2013; Schmeller et al. 2015). An EBV is thus a critical biological variable that characterizes change in an aspect of biodiversity across multiple species and ecosystems, functioning as the interface between raw data and the calculated indicators (Pereira et al. 2013; Brummitt et al. 2016; Proença et al. 2016; Mihoub et al. 2017). For instance, species abundance provides data for indicators such as the Living Planet, Wild Bird, and Red List indices (LPI, WBI, and RLI) (Pereira et al. 2013). In the proposed monitoring network, main raw data were systematically collected, including the name of species, location and number of individuals, type and vegetation of habitats, weather condition, and categories (infra-structure development, resources exploitation, pollution, hunting, tourism, agriculture, husbandry and fishery, etc.) and extent (strong, moderate, low or non) of anthropogenic disturbance. The corresponding EBVs that can be generated by the proposed monitoring network encompass abundance and distribution, taxonomic diversity, habitat structure and quality, and phenology. Thus, the monitoring network here can notably contribute to mapping of EBVs at global level.

The proposed monitoring scheme has received wide support from the Central Government, Ministry of Environmental Protection (MEP), Ministry of Finance (MF) and the scientific community from China. With an annual financial allocation of approximately 
USD 5.8 million from MEP and MF, the monitoring scheme proposed in this study has taken into effects as China Biodiversity Observation Network (China BON). Under the planning and coordination of Nanjing Institute of Environmental Sciences affiliated to MEP, China BON has attracted approximately 3500 trained biologists, protected area managers and volunteer citizen scientists from over 400 universities, research institutes, protected areas and civil societies to get involved in field monitoring of biodiversity, currently consisting of mammals, birds and amphibians. The pilot implementation adopted national standards and field protocols for biodiversity monitoring promulgated by MEP. 441 monitoring sites were selected and applied for monitoring with $>9000$ line transects and point transects. It is noted that one of the key challenges in designing a long-term monitoring framework is program sustainability (Barrows et al. 2014). To enhance the sustainability of China BON, we coupled trained biologists with volunteer citizen scientists. At least one professional biologist was included in each monitoring team while well trained volunteers are also involved to extend limited staff and budgets for the long-term monitoring goal (Barrows et al. 2014). At present, China BON's Work Plan has been approved by the State Council of China. In particular, the opersationalization of biodiversity monitoring networks based on this study has been listed as one of the key action plans by China National Economy and Social Development Planning in the 13th Five-Year Plan and approved by the National People's Congress in 2016. It is imperative to continuously maintain national biodiversity monitoring networks. Their success depends on the commitment of the whole society, including scientific communities, private sectors, governments and the public.,

Acknowledgements This work was funded by the National Key Technologies Research and Development Programme (environmental project 201409061, Grants 2008BAC 39B06 and 2008BAC39B01) and the Biodiversity Conservation Programme of China. The authors would thank helpful comments from two anonymous reviewers and Dr. Dirk Schmeller (Senior Editor).

Open Access This article is distributed under the terms of the Creative Commons Attribution 4.0 International License (http://creativecommons.org/licenses/by/4.0/), which permits unrestricted use, distribution, and reproduction in any medium, provided you give appropriate credit to the original author(s) and the source, provide a link to the Creative Commons license, and indicate if changes were made.

\section{References}

Amorim F, Carvalho SB, Honrado J, Rebelo H (2014) Designing optimized multi-species monitoring networks to detect range shifts driven by climate change: a case study with bats in the North of Portugal. PLoS ONE 9:e87291

Balmford A, Green RE, Jenkins M (2003) Measuring the changing state of nature. Trends Ecol Evol $18: 326-330$

Barrows CW, Hoines J, Fleming KD et al (2014) Designing a sustainable monitoring framework for assessing impacts of climate change at Joshua Tree National Park, USA. Biodivers Conserv 23:3263-3285

BDM Coordination Office (2014) Swiss biodiversity monitoring BDM. Description of methods and indicators., Environmental studies no. 1410Federal Office for the Environment, Bern

Brooks TM, Mittermeier RA, da Fonseca GAB, Gerlach J, Hoffmann M, Lamoreux JF, Mittermeier CG, Pilgrim JD, Rodrigues ASL (2006) Global biodiversity conservation priorities. Science 313:58-61

Brummitt N, Regan EC, Weatherdon LV et al (2016) Taking stock of nature: essential biodiversity variables explained. Biol Conserv. doi:10.1016/j.biocon.2016.09.006

Butchart SHM, Walpole M, Collen B et al (2010) Global biodiversity: indicators of recent declines. Science 328:1164-1168 
Cabeza M, Moilanen A (2001) Design of reserve networks and the persistence of biodiversity. Trends Ecol Evol 16:242-248

Campbell SP, Clark JA, Crampton LH, Guerry AD, Hatch LT, Hosseini PR, Lawler JJ, O’Connor RJ (2002) An assessment of monitoring efforts in endangered species recovery plans. Ecol Appl 12:674-681

Carvalho SB, Gonçalves J, Guisan A, Honrado JP (2016) Systematic site selection for multispecies monitoring networks. J Appl Ecol 53(5):1305-1316

CBD (2010) Decision X/2, the strategic plan for biodiversity 2011-2020 and the Aichi biodiversity targets. Nagoya, Japan, 18-29 Oct 2010

Colwell RK, Coddington JA (1994) Estimating terrestrial biodiversity through extrapolation. Phil Trans R Soc Lond B 345:101-118

Development Core Team R (2012) R: a language and environment for statistical computing Vienna, Austria. R Foundation for Statistical Computing, Vienna

DeWan AA, Zipkin EF (2010) An integrated sampling and analysis approach for improved biodiversity monitoring. Environ Manag 45:1223-1230

Dobson AP, Rodriguez JP, Roberts WM, Wilcove DS (1997) Geographic distribution of endangered species in the United States. Science 275:550-553

Faith DP, Carter G, Cassis G, Ferrier S, Wilkie L (2003) Complementarity, biodiversity viability analysis, and policy-based algorithms for conservation. Environ Sci Policy 6:311-328

Gerber LR, DeMaster DP, Kareiva PM (1999) Gray whales and the value of monitoring data in implementing the U.S. endangered species act. Conserv Biol 13:1215-1219

Green RE, Balmford A, Crane PR, Mace GM, Reynolds JD, Turner K (2005) A framework for improved monitoring of biodiversity: responses to the world summit on sustainable development. Conserv Biol 19:56-65

Harris SJ, Massimino D, Newson SE, Eaton MA, Marchant JH, Balmer DE, Noble DG, Gillings S, Procter D, Pearce-Higgins JW (2016) The breeding bird survey 2015., BTO research report 687British Trust for Ornithology, Thetford

Haughland DL, Hero JM, Schieck J, Castley JG, Boutin S, Solymos P, Lawson BE, Holloway G, Magnusson WE (2010) Planning forwards: biodiversity research and monitoring systems for better management. Trends Ecol Evol 25:199-200

Hauser CE, Pople AR, Possingham HP (2006) Should managed populations be monitored every year? Ecol Appl 16:807-819

Honrado JP, Pereira HM, Guisan A (2016) Fostering integration between biodiversity monitoring and modelling. J Appl Ecol 53:1299-1304

Kéry M, Schmid H (2004) Monitoring programs need to take into account imperfect species detectability. Basic Appl Ecol 5:65-73

Liu JG, Diamond J (2005) China's environment in a globalizing world. Nature 435:1179-1186

Liu JG, Ouyang ZY, Pimm SL, Raven PH, Wang XK, Miao H, Han NY (2003) Protecting China's biodiversity. Science 300:1240-1241

MacKenzie D (2006) Modeling the probability of resource use: the effect of, and dealing with, detection a species imperfectly. J Wildl Manag 70:367-374

Mihoub JB, Henle K, Titeux N et al (2017) Setting temporal baselines for biodiversity: the limits of available monitoring data for capturing the full impact of anthropogenic pressures. Sci Rep 7:41591

Ministry of Environmental Protection of China (2014) China's fifth national report on the implementation of the convention on biological diversity. https://www.cbd.int/doc/world/cn/cn-nr-05-en.pdf). (China Environmental Science Press, Beijing)

Noon BR, Bailey LL, Sisk TD, McKelvey KS (2012) Efficient species-level monitoring at the landscape scale. Conserv Biol 26:432-441

Orme CDL, Davies RG, Burgess M et al (2005) Global hotspots of species richness are not congruent with endemism or threat. Nature 436:1016-1019

Pereira HM, Cooper HD (2006) Towards the global monitoring of biodiversity change. Trends Ecol Evol 21:123-129

Pereira HM, Ferrier S, Walters M et al (2013) Essential biodiversity variables. Science 339:377-378

Proença V, Pereira HM, Martin LJ et al (2016) Global biodiversity monitoring: from data sources to essential biodiversity variables. Biol Conserv. doi:10.1016/j.biocon.2016.07.014

Reyers B, van Jaarsveld AS, Krüger M (2000) Complementarity as a biodiversity indicator strategy. Proc R Soc Lond B 267:505-513

Schmeller DS, Julliard R, Bellingham PJ et al (2015) Towards a global terrestrial species monitoring program. J Nat Conserv 25:51-57

Shea K, Mangel M (2001) Detection of population trends in threatened coho salmon (Oncorhynchus kisutch). Can J Fish Aquat Sci 58:375-385 
Tittensor DP, Walpole M, Hill SL et al (2014) A mid-term analysis of progress toward international biodiversity targets. Science 346:241-244

Vicente J, Alagador D, Guerra C et al (2016) Cost-effective monitoring of biological invasions under global change: a model-based framework. J Appl Ecol 53:1317-1329

Williams P, Faith D, Manne L, Sechrest W, Preston C (2006) Complementarity analysis: mapping the performance of surrogates for biodiversity. Biol Conserv 128:253-264

Wu ZY, Sun H, Zhou ZK, Li DZ, Peng H (2011) Floristics of seed plants from China. Science Press, Beijing

$\mathrm{Xu}$ HG (2013) Introduction to monitoring of species resources. Science Press, Beijing

Xu HG, Wu J, Liu Y, Ding H, Zhang M, Wu Y, Xi Q, Wang L (2008) Biodiversity congruence and conservation strategies: a national test. Bioscience 58:632-639

Xu HG, Ding H, Wu J (2012) Introduction to ecological and biodiversity monitoring in China. In: Nakano S, Yahara T, Nakashizuka $\mathrm{T}$ (eds) The biodiversity observation network in the Asia-pacific region: toward further development of monitoring. Springer, Tokyo, pp 65-70

Xu HG, Cao MC, Wu J, Ding H (2013) Assessment report on biodiversity baseline in China. Science Press, Beijing

Xu HG, Cao MC, Wu J et al (2015) Determinants of mammal and bird species richness in China based on habitat groups. PLoS ONE 10:e0143996

Xu HG, Cao MC, Wu Y et al (2016) Disentangling the determinants of species richness of vascular plants and mammals from national to regional scales. Sci Rep 6:21988

Yang W, Dietz T, Kramer DB, Ouyang Z, Liu J (2016) An integrated approach to understanding the linkages between ecosystem services and human well-being. Ecosyst Health Sustain 1(5):1-12

Yoccoz NG, Nichols JD, Boulinier T (2001) Monitoring of biological diversity in space and time. Trends Ecol Evol 16:446-453

Zhang RZ (2011) Zoogeography of China. Science Press, Beijing 